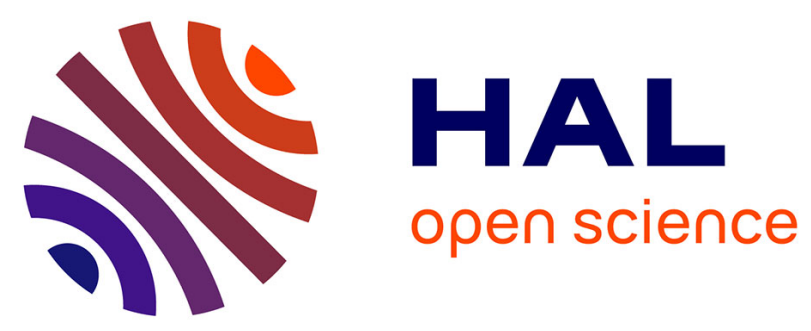

\title{
Social network analysis: New ethical approaches through collective reflexivity. Introduction to the special issue of Social Networks
}

Paola Tubaro, Louise Ryan, Antonio A. Casilli, Alessio D'angelo

\section{- To cite this version:}

Paola Tubaro, Louise Ryan, Antonio A. Casilli, Alessio D'angelo. Social network analysis: New ethical approaches through collective reflexivity. Introduction to the special issue of Social Networks. Social Networks, 2021, Recent ethical challenges in social network analysis, 67, pp.1-8. 10.1016/j.socnet.2020.12.001 . hal-03090287

\section{HAL Id: hal-03090287 \\ https://hal.science/hal-03090287}

Submitted on 29 Dec 2020

HAL is a multi-disciplinary open access archive for the deposit and dissemination of scientific research documents, whether they are published or not. The documents may come from teaching and research institutions in France or abroad, or from public or private research centers.
L'archive ouverte pluridisciplinaire HAL, est destinée au dépôt et à la diffusion de documents scientifiques de niveau recherche, publiés ou non, émanant des établissements d'enseignement et de recherche français ou étrangers, des laboratoires publics ou privés. 


\title{
Social Network Analysis: new ethical approaches through collective reflexivity
}

Introduction to the Special Issue of Social Networks

Paola Tubaro, LRI-TAU, CNRS, Université Paris-Saclay, Inria, France

Louise Ryan, London Metropolitan University, UK

Antonio A. Casilli, 13, Telecom Paris, Institut Polytechnique de Paris, Paris, France

Alessio D’Angelo, University of Nottingham, UK

This paper is an introduction to the special issue of Social Networks on Recent Ethical Challenges in Social Network Analysis.

Our initiative follows the organization of a two-day event in Paris, in December 2017, on the same topic. We acknowledge Maison des Sciences de l'Homme Paris-Saclay for generous funding, and British Sociological Association as well as Institut d'Etudes Avancées, Association Française de Sociologie and European Network on Digital Labour for logistical and organizational support.

\begin{abstract}
Research in social network analysis (SNA) faces unprecedented ethical challenges today due to both technological developments ('big' data) and a growing tendency toward institutionalization of ethics governance. We argue that a suitable response requires a more comprehensive approach to SNA ethics, and we identify two main paths toward this goal. First, we need to recognize the breadth of the subject, no longer limited to anonymity and consent. Second, we need to encourage the active participation and contribution of SNA scholars. We advocate a need for greater reflexivity at both individual and collective levels, whereby researchers can learn from their own and their peers' experiences, and foster a more ethically 'virtuous' approach within the whole SNA community.
\end{abstract}




\section{Introduction}

The close of the fifteenth anniversary of the special issue of the journal Social Networks on 'Ethical dilemmas in social network research ${ }^{1}$ provides the chance for both a critical assessment and a reconceptualization of the matters at stake. If the motivation for that earlier publication was a glaring lack of references and sources for practitioners of social network analysis (SNA), on the contrary today's ethical debate is typified by a multitude of competing approaches. When we initially launched the project of a new special issue on ethics in SNA, we did it through an open call for contributions directed to our whole scholarly community. We thought this would be an ideal time to reflect on our experiences, difficulties, and approaches, and to share what many of us have learned individually to advance everyone's understanding of ethics applied to SNA research.

In the mid-2000s, researchers were in desperate need for guidance in matters as diverse as AIDS epidemiology, collaboration with commercial companies (including nascent internet platforms), and military sponsorship. After lively debates on the SOCNET mailing list ${ }^{2}$, it was decided to offer journal space to the 'ethical imagination' of SNA theorists, in an effort to map the state of the art and move forward (Breiger, 2005). Since then, questions have mushroomed while answers have not kept pace, largely as a side effect of the dramatic impact of online networking on SNA. Technology has opened up new avenues for research with 'big data', but at the expense of higher threats to confidentiality and anonymity, all the more so as these data are connected, and leakages from one individual data point (such as a profile on an online service) may ultimately expose all its contacts. Digital networks have also transformed people's perceptions of their relationships and of their economic and symbolic value, changing their attitudes toward, and expectations of, SNA research. In particular, growing public concern around data protection and privacy makes it more difficult to justify the collection of relational information - with names and attributes of network members. Another consequence of ubiquitous digitalization is greater difficulty to communicate about research on non-technologymediated networks, and the misunderstandings that derive from the common confusion between social networks and social media.

The institutional context has also changed. Over the past decade, research governance increasingly enacted documentation rules and administrative procedures, resulting in a formulaic 'tick box' approach to research ethics (see Molina and Borgatti, 2019, in this special issue). The current approaches of ethical reviews and ethics committees (commonly called IRB, Institutional Review Board, in North America and REC, Research Ethics Committee, in Europe) appear to reduce ethics to a narrow series of questions around methodology, access, consent and anonymity (Guillemin, Gillam, Rosenthal and Bolitho, 2012; Guta, Nixon and Wilson, 2013). The guidelines laid down by such ethics committees may be overly regulatory, and guidelines borrowed from the health and life-sciences may not be appropriate to the more flexible and fluid nature of social science research. Being based on an 'ex-ante' approach, such procedures also tend to ignore the fact that researchers are just as likely to face difficult and unanticipated ethical dilemmas after they enter the research field (see D'Angelo and Ryan, 2019, in this special issue) and in later phases of research dissemination (see contribution by Tubaro, 2019). While these trends are not unique to SNA, the resulting restrictions and rigidities are particularly demanding for our field, where the key principles of research ethics anonymity and informed consent - are notoriously more difficult to apply (Kadushin, 2005; Kadushin, 2012, chap. 11; Robins, 2015, chap. 7).

\footnotetext{
${ }^{1}$ Social Networks, Volume 27, Issue 2, May 2005.

${ }^{2}$ SOCNET (www.insna.org/socnet) is the mailing-list of INSNA, the International Network for Social Network Analysis.
} 
In parallel, technological developments and globalization have brought new voices into the debate. Tech companies have pushed the agenda toward new and better-suited ethical frameworks for digital information and artificial intelligence (Jobin, lenca and Vayena, 2019), sometimes in partnership with public research actors. On their side, governments have also established new priorities in terms of, for example, border control and economic sovereignty, inevitably affecting the choices of researchers and their institutions. While mitigating researchers' dependency on narrow bio-medical research ethics, this pluralism has also introduced confusion and uncertainty. Thus, contemporary scholars are confronted with irreconcilable constraints and conflicting approaches, which make their task all the more sensitive.

It is urgent to extend previous efforts to establish a more comprehensive approach to SNA ethics, and this is precisely the goal of the present special issue. Two main paths lie ahead to provide new perspectives, and the remainder of this article discusses them thoroughly. Firstly, we can no longer be content with addressing anonymity and consent, despite the fact that they remain particularly challenging in SNA, and still call for creative and forward-thinking solutions. Today, ethics in our field extend to a number of other issues. Communicating results at the end of SNA research can be as challenging as obtaining consent at the beginning (Tubaro, this special issue). The force of network visualizations may get around anonymity and reveal identities, or otherwise emotionally affect stakeholders (Tubaro, Ryan and D'Angelo, 2016; contribution by D'Angelo and Ryan in this special issue). SNA research is particularly sensitive in business settings (Cronin, Rocha, Perra, Zhu, Pallotti, Gorgoni, Conaldi and De Vita, 2020, this special issue) and wherever power asymmetries and profit motives may distort the research (Maya-Jariego, Alieva and Holgado, 2019, this special issue). Even the health sciences face unprecedented challenges when they use network data from social media platforms (Chu, Colditz, Sidani, Zimmer and Primack, 2019, this special issue), or when respondents have grown more privacy-aware and willing to protect their contacts (Rudolph and Young, 2019, this issue).

Secondly, SNA ethics can only progress through the active participation and contribution of the scholars who practice it. As the increasingly bureaucratic nature of ethics committees slows down our capacity to address ever-evolving, multi-stakeholder challenges, a bottom-up approach is most suitable to map the concrete issues that researchers encounter, and to leverage their experiences and know-how to develop suitable responses. In this article, we make the case for greater reflexivity among social network researchers. Beyond a tick box, formulaic approach to obtaining ethical approval, it is necessary for researchers to reflect on the complexity of ethical dilemmas at every stage of the research process. We suggest this process needs to be transparent and shared collectively with the wider research community to foster a truly collective reflexivity. In arguing that developing a reflexive way of thinking about the complexities of field research will enable a more ethically 'virtuous' approach, we aim to make an original contribution to research ethics in the field of SNA.

Guillemin and Gillam (2004) distinguish between what they call 'procedural ethics' (ethics governance) and 'ethics in practice' (the actual ethical dilemmas encountered in the research field). Rather than simply adhering to hard and fast ethical guidelines, such ethical dilemmas may involve antagonistic principles that have to be negotiated and resolved on a case-by-case basis (Cronin, Rocha, Perra, Zhu, Pallotti, Gorgoni, Conaldi and De Vita, 2020, this special issue). Instead of seeing ethics as straightforward and universal, researchers - whether they work with quantitative or qualitative methods - need to be trained to become more reflexive about the intricacies of ethics at every stage of the research process (Comstock, 2012). In other words, researchers need to know what it means to become a 'virtuous researcher' in the complex and messy reality of the social world. We argue that researchers should not be left alone in this undertaking. Beyond training, they need continuing access to the knowledge resources embedded in their scholarly community. We call for a 
virtuous SNA community in which the sharing of members' experience is valued and encouraged, and all can benefit from others' reflective accounts, while transparently offering their own ethical insights in return. In this respect, mutual learning between scholars adopting different disciplinary angles or methodological approaches - qualitative, quantitative, or mixed (Tubaro, Ryan and D'Angelo, 2016) can be particularly beneficial in developing more nuanced and comprehensive understandings of the ethics of SNA.

The articles in this special issue are a first step in this direction, aiming to constitute an initial set of references to raise awareness, support reflexivity, and foster further debate. The special issue was preceded by a two-day international workshop (with the same title) in Paris in December $2017^{3}$. We were very pleased with colleagues' responses to our call for papers and attendance at the event. Participants felt it was a timely discussion - at a moment in which Europe was preparing for the promulgation of the European General Data Protection Regulation (GDPR) and the global digital industry was gradually becoming aware of the need for some ethical anchoring. The success of this event motivated us to bring the initiative to the next level with a publication, to give workshop speakers an opportunity to refine their papers, and to involve other interested colleagues. The editors of Social Networks accepted our proposal and we diffused a call for papers in spring 2018. We did a few rounds of informal, internal reviews to get papers to a very high standard before submitting them to the journal. All prospective contributors volunteered to peer-review one or more of the other submitted manuscripts - in a deliberate effort to learn from one another. The special issue is the result of this exercise, and we gratefully acknowledge the outstanding contribution of authors, workshop participants, external anonymous reviewers, and the journal's editors.

This collective effort was underpinned by the recognition that SNA raises very particular issues which, in turn, challenge ideas often taken for granted in the wider social sciences. This has always been the case - though has not always attracted the necessary attention - but it is even more so in the context of contemporary societies, which are 'digital' and interconnected in an increasing and unprecedented way. In the next three sections, we start exploring these aspects - which are further examined in the articles included in this special issue. We then proceed by fleshing out our argument about reflexivity and 'virtuous research', and propose some ways forward for the SNA research community.

\section{The difficult relationship between SNA and research ethics}

Although, over time, research practices have tended to align along a set of standards that all social researchers are expected to comply with, typically under the scrutiny of institutional bodies, this has not removed some major underlying tensions. On the contrary, research areas such as SNA often bring these tensions to the surface. For example, social networks scholars are frequently in need of more flexible procedures for routine requirements such as anonymity. Their main argument in favour of trading anonymity for mere ex-post de-identification is that, especially in whole network studies, names (or other unique identifiers) are necessary to match senders and receivers of ties, and can only be removed at a later stage. As Charles Kadushin (2012: 188) puts it, names are not incidental but the very point of network data collection. This need has repeatedly been recognized, suggesting that anonymity is not an absolute imperative, but a guiding principle that has to be assessed in the

\footnotetext{
${ }^{3}$ Our initiative was originally inspired by an insightful conversation with Dr Bernie Hogan, Oxford Internet Institute, who first suggested the need for more work on ethics in SNA. We thank him for sharing these ideas and contributing to the process. Dr Hogan was a keynote speaker at our event, together with Prof José Luis Molina, Universitat Autònoma de Barcelona. We acknowledge Maison des Sciences de l'Homme Paris-Saclay for generous funding, and Institut d'études avancées de Paris, British Sociological Association, Association Française de Sociologie as well as European Network on Digital Labour for logistical and organizational support.
} 
overall context of a study. This argument, however, does not always convince ethics committee members, especially when they are very risk-averse or unfamiliar with SNA. Their point is that accidental re-identification may have consequences on study participants. In such cases, researchers are asked to introduce additional procedures that may be cumbersome, or even conducive to loss of crucial information.

Another standard requirement that may turn out to be problematic for SNA scholars is informed consent, which is difficult to obtain from the people who are nominated as contacts by respondents, and thus do not formally qualify as 'participants' in the study. Requests to waive consent if strict confidentiality is guaranteed often rest on the idea that $A^{\prime}$ 's nominations (of individuals $B, C$, etc.) are representations of the social structure as seen by $A$ and therefore, they constitute $A^{\prime}$ 's data, not B's or $C^{\prime}$ 's, which implies that only A's consent should be sought (Robins, 2015: 152). If this argument is often accepted, it is also debatable, insofar as knowledge of $A^{\prime}$ 's nominations may have indirect repercussions on $B$ and $C$. Any breach of confidentiality involves high risks, for example when ties between individuals presuppose joint involvement in sensitive or illicit activities.

Confidentiality is a tricky subject in SNA, as there are more ways to re-identify study participants than in other social science studies. Network visualizations may reveal identities as knowledgeable stakeholders are often able to make plausible guesses about the most central or most peripheral individuals. This may be especially the case in studies where the numbers of participants are relatively small, for example in qualitative studies. Even when node colours or shapes are deidentified and reflect broad categories such as gender or department, it may be easy to recognize 'the only high-ranking woman in the Boston office' (Borgatti, Everett and Johnson, 2013: 48). In some cases, non-participants can be re-identified as well. Especially if they occupy a central position in a given social setting (like a school or company) their absence from visualization can become conspicuous, as their mates or colleagues can infer who they are. In short, the power of visualization is also a potential threat: "Network analysis does its "magic" by making visible what was not visible before and reveals connections between individuals and groups who may not have wanted this information to be made public' (Kadushin, 2012: 188).

Although these examples may lead to the conclusion that SNA is more sensitive to ethical issues than other areas of social science, we believe it is also an ideal lens through which we can clearly see that even well-established principles are contingent and need to be adapted to context. Researchers who managed to convince ethics committees and study participants had to negotiate practical solutions on a case-by-case basis, as general norms are seldom transposable to new circumstances. Even when umbrella protocols are in place, it is crucial to reflect upon different approaches and weigh costs and benefits. Importantly, negotiation does not only mean persuading committees to soften their approach, or nudging reluctant target populations into participation in a study. It is an opportunity to raise issues that we are aware of as specialists, but that escape institutions and other stakeholders. For example, Kadushin (2012: 187) notes that ethics committees often overlook the organizational structures in which individual ties are embedded, as well as the potential consequences of commissioned research which might later be used for internal management purposes (Borgatti and Molina, 2005). Likewise, study participants often underestimate the potential consequences of naming friends and contacts, and 'name generator' questions sometimes seem less problematic to them than survey questions on, say, their income or health status. It is up to the researcher, then, to adopt a reflexive approach to the risks and find ethical ways to mitigate them.

It is for this reason that SNA researchers need specific guidance and examples, which the 2005 Social Networks special issue aimed to provide. This endeavour set the example for later work and in this sense, it was successful. Among the several SNA manuals published afterward, some have a full chapter (Kadushin, 2012, chap. 11; Robins, 2015, chap. 7) or at least a section (Borgatti, Everett and Johnson, 2013: 46-48) dedicated to ethical dilemmas, sometimes with case studies. In addition to 
giving some advice on how to secure institutional approval, these books laudably alert readers about the more complex, field-specific issues discussed above. Thus, a newcomer has the opportunity to receive introductory training in this area. Yet problems with IRB or REC applications are still common subjects of discussion on the SOCNET mailing list, a round table at the 2015 Sunbelt conference was devoted to this topic, and there is still a lack of agreed guidelines. The details of ethical protocols and decisions are not commonly reported in scientific publications, and researchers can hardly learn from one another. A lot is left to their ability to negotiate their strategies individually and locally. There is clear need for a more open reflection on ethical dilemmas at every stage of the research process and to explore how these reflections can be shared with the wider SNA research community. These persisting gaps have serious consequences with the new challenges that SNA faces today, and that constitute the core of our contribution, both in the remaining pages of this introduction and in the rest of the present special issue.

\section{Digitization and its challenges to SNA research}

As we briefly said above, digitization has transformed the research landscape, with repercussions on SNA and its ethical practices. Once the nature and relevance of computer-enabled linkages were admitted (Wellman, 2001), research has invested in the study of relational data from digital platforms such as Facebook and Twitter. This massive shift shook established certainties about anonymization, privacy and informed consent, at least at the beginning. In this very journal, a controversial paper by Lewis, Kaufman, Gonzalez, Wimmer and Christakis (2008) illustrates the problem. The authors had the - then unprecedented - opportunity to obtain Facebook profiles and network data of a whole cohort of Harvard college students, to repeat the data collection every year, and to match this information with students' housing records obtained from the University. Although the researchers secured ethical approval from their institution and acted in good faith throughout the process, embarrassment followed as their data subjects were re-identified within days after publication. Conflating data availability and publicness (albeit in a digital service accessible only to signed-up users) is a serious misunderstanding of the nature of the social process at stake here. Like many at the time, the researchers (and the members of their ethics committee) had naively thought that 'their data collection methods were unproblematic since the "information was already on Facebook"' (Zimmer, 2010: 323).

The networked nature of online communications is of particular concern as data not only describe individuals, but also their social contacts and communication patterns (Hoser and Nitschke, 2010: 182). Misuses may have consequences that extend far beyond academic debates, and we will recall here two exemplary (though fortunately rare) cases. One is the widely known Cambridge Analytica scandal that erupted in 2018. With the help of an academic and allegedly for research purposes, the company hired low-paid workers on Amazon Mechanical Turk to take a survey and to give access to their Facebook profiles - which allowed collecting personal information on each of their unaware and non-consenting contacts. This harvesting of personal data from several millions of users was subsequently deemed illegal and contrary to Facebook rules. It caused public outcry when it was revealed that these data had been monetized and used for political advertising in the UK Brexit campaign and in the USA presidential elections of 2016. Another scandal shook French-speaking Europe in the summer of 2018, when Belgian NGO EU Disinfo Lab mapped Twitter controversies around so-called 'Benalla affair' (a security officer of French President Emmanuel Macron, involved in the beating of protesters during demonstrations). The NGO used the well-known Louvain community-detection algorithm to distinguish four classes, and associated them to political parties and perspectives, specifically looking for linkages to disinformation sources and Russian influences. What triggered the massive reaction of users - and of data protection authorities - was the release 
(later withdrawn) of the full, non-pseudonymized list of Twitter accounts, each associated to one of the contested classes of political affiliations.

In light of these high-profile cases, the academic community has not remained passive, and progress is being made both practically and theoretically. There is growing consensus around the idea of 'contextual' privacy (Nissenbaum, 2009), whereby information shared on an online social networking site is not intended for other uses and cannot be taken as 'public' in the same way as, say, a formal speech deliberately intended to reach out to large audiences. Beyond formal informed consent, researchers are now globally more mindful of the expectations of privacy that users of online networking sites might have (Chu, Colditz, Sidani, Zimmer, and Primack, 2019, this special issue; Williams, Burnap and Sloan, 2017).

However, awareness may not be enough when data have commercial value, and generate formidable (and potentially misleading) incentives to use them for profit. These tensions are not new, and in the previous Social Networks special issue, Borgatti and Molina (2005) discuss how corporate actors aspire to use network information for purposes ranging from internal staff management to competition monitoring. These issues have now become more extreme, because large volumes of highly detailed digital data can be gathered quickly and cheaply. For example, instead of having respondents painstakingly complete a name generator, Cambridge Analytica used a software application that automatically mapped their network of Facebook friends. Even running a network survey or an experiment has become easier and cheaper, as one can tap into the large reservoir of digital labourers of platforms such as Amazon Mechanical Turk, Microworkers or Clickworker. But low costs come with ethical challenges. Using these services raises the dual questions of fair treatment of the online workforce that generates or prepares data for analysis (Fort, Adda and Bretonnel-Cohen, 2011), and confidentiality of the data that online workers process, which may include personal information (Chu, Colditz, Sidani, Zimmer, and Primack, 2019, this special issue).

Not only may researchers fall into temptation, but they may themselves become victims of competition around data. Precisely because data are valuable assets, the private companies that control them are increasingly less willing to share them, and restrict access even for non-profit scholarly purposes. Online social networking services like Facebook, Linkedln and Twitter seek progressively more control and restructure their APIs (Application Programming Interface, their main technical means to interact with externals) to limit third-party access to data about users' networks of friends (Hogan, 2018). The prophecy of a 'data deluge', popular around 2010, has now given way to silos in which researchers are unequal in terms of their access to data (Bastin and Tubaro, 2018), and replicability of findings is harder to ensure. Potential conflicts of interest become more likely and widespread than before, and publicly-funded research, once leader in the production and analysis of network data, loses its primacy relative to corporate R\&D services in digital industries.

In some cases, exclusion of SNA scholars misses the opportunity to leverage valuable experience developed over decades of network data management. An example of this difficulty is the controversy surrounding the introduction of data-intensive proximity tracing apps developed in the wake of the 2020 Covid-19 pandemic. Proximity tracing is a form of automated contact tracing that many governments have put in place to complement symptom checkers, quarantine monitoring and mobility report tools. Presented as an alternative to privacy-intrusive, geo-localized tracking, tracing consists in identifying ties between suspected Covid-19 patients (egos) and their contacts (alters), and notifying them in case one member of this personal network is tested positive. Amid fears that these apps would gather huge volumes of sensitive health information, a European consortium of cryptography experts developed a set of 'privacy-preserving' protocols. The hegemonic one, dubbed DP-3T, prides itself of storing data about ties between egos and alters on individual mobile devices, rather than on government-run servers. Nevertheless, the involvement of tech giants Apple and 
Google, who offered to provide a common API to make country-specific apps interoperable, adds new risks as installation prompts users to agree to the collection of anonymous metrics about the effectiveness of contact-tracing processes. Contact-tracing mobile apps have turned out to be an arena where diverging approaches to public health policies, privacy, and the role of corporations and governments go head-to-head. SNA scholars have been largely inaudible in this arena, and that is all the more surprising given that the data collected by these apps are network-specific. In this case, ethical insights coming from researchers having met similar challenges before may have benefited the general public and informed public policies.

Of course, that is not to suggest that all SNA has switched to use of online data, and many researchers still rely on offline, smaller-scale questionnaires and interviews, whether qualitative or quantitative (see for example Rudolph and Young, and Maya-Jariego, Alieva and Holgado, this special issue). Yet even in research that continues to be set in offline environments such as schools and companies, technology has fundamentally changed our practices. The popularity of social networking sites and apps has reshaped public representations of networks, influenced people's willingness to take part in studies, and inflected their assumptions about network data collection (for a discussion see D'Angelo and Ryan, in this special issue). In a sense, this is good news: for example, growing familiarity with graph visualizations often motivates people to participate and facilitates recruitment. But because people conflate networks with online networking sites such as Facebook and Twitter, they may struggle to understand that social networks are structures of human relationships, and that they underlie all human collectives, not only digitally-mediated ones. Overall, the non-digital, historical know-how of our scholarly community has lost visibility compared to the growing popularity of studies of online networks. It is another way through which the balance of power is shifting toward the tech giants that own online social networking sites.

Experiences with online networking also shape participants' concerns and may induce them to limit the network information they give to researchers. Recurrent privacy scandals and data leaks involving tech companies are one of the reasons why people - especially in stigmatized populations are more often unwilling to disclose information that may identify their contacts. Rudolph and Young (this issue) document how this happens in the case of network studies among men who have sex with men, and showcase solutions to alleviate the problem.

As a result of habits learned on the Internet, participants to SNA studies often have strong ideas about their networking skills, the value of their contacts, and the portrait of themselves as effective networkers. These prior expectations may make the research experience much more sensitive. As D'Angelo and Ryan show in this special issue, a (fully offline) interview encounter with a researcher may shatter participants' carefully constructed representations of themselves, exposing them to discomfort or embarrassment if, for example, a visualization shows that their networks are less rich or less diverse than they imagined them to be. Researchers, then, have to thoughtfully use their judgement and ethical sensitivity and sensibility to manage the messy reality of collecting network data from human participants.

\section{Institutions and their demands}

The other main tendency that reconfigures the context in which SNA is undertaken today is the overbureaucratization and growing standardization of ethics. As mentioned above, it is useful to distinguish between the bureaucracy of ethics governance and ethics in the research field or as Guillemin and Gillam (2004) label them, 'procedural ethics' and 'ethics in practice'. In many cases, the bureaucratization of ethics committees has meant the power to act as gate keepers in either 
sanctioning or controlling access to research and, indeed, research funding (Guta, Nixon and Wilson, 2013; Molina and Borgatti, 2019, this special issue).

In part, this process has been driven by legislative changes, most prominently with the entry into force of the European General Data Protection Regulation (GDPR) in 2018 and the California Consumer Privacy Act (CCPA) in 2020, which have imposed strong data protection rules for any personal information collected by, or about, EU and US residents respectively. One reason for their adoption was the need to respond to some drawbacks of digitization, notably the many privacy scandals that have interspersed the history of digital companies. Neither GDPR nor CCPA are specifically about regulating research, and do not cover all aspects of ethics, but they tend to apply to most cases in which personal data are collected, used or transferred-especially in an online setting. Both pieces of legislation have set high standards and thus raised fears among researchers that they may further constrain their activities. However, they can also be seen as good news for research, because they offer responses to (some of) the difficult cases that arise with online data collection, and authorize alternatives to informed consent - which as discussed above, is particularly challenging in SNA. Indeed, GDPR indicates six possible legal bases for processing personal data, some of which apply to research: when consent cannot be sought, possible legal grounds can be 'public task' (that is, activities carried out in the public interest) or the legitimate interest of the controller. In practice, though, it is not straightforward to navigate the law, and researchers need expert legal advice to ensure compliance without renouncing scientific quality. Molina and Borgatti (this special issue) suggest the current trend toward increasing institutionalization of research ethics governance systems is unhelpful, as it tends to prioritize bureaucratic needs instead of providing genuine support.

Corporate governance of digital data provides alternative, and possibly conflicting, sources of guidance. With the recent boom in artificial intelligence (Al), tech companies have sparked the proliferation of ethical principles and guidelines. These emerging discourses surrounding 'ethical $\mathrm{Al}^{\prime}$, 'unbiased algorithms' or 'privacy-preserving' data collection are, according to several analyses, performative in nature, as they fail to acknowledge the limitations of contemporary $\mathrm{Al}$ and the requirement to comply with strict accountability frameworks (Kerr, Barry and Kelleher, 2020). Especially high profile initiatives, such as Facebook's 2019 'Supreme Court' for content moderation (Ingram, 2020), have been criticised as examples of ethical washing mainly aimed at avoiding state regulation (Ochigame, 2019). Even when not strictly linked to these initiatives, SNA researchers may find themselves constrained by the way corporate actors have steered the ethical conversation. Since 2015, at least eighty-four charters for ethical Al and data governance have been published. Despite broad consensus on basic principles such as transparency, justice, non-maleficence and privacy (which also happen to be staples of classical liberal thinking), these approaches to 'ethical $\mathrm{Al}^{\prime}$ disregard values that point to persisting environmental and social issues such as sustainability, energy efficiency, solidarity, social security, and dignity (Jobin, lenca and Vayena, 2019).

This complex context, and the ensuing power imbalances, may produce contradictory injunctions. Research funding bodies increasingly demand to generate 'impact', as 'the demonstrable contribution that excellent research makes to society and the economy' (ESRC, 2020). In principle, maximising opportunities for social and economic impact is not at odds with ethics. But here, 'procedural ethics' and 'ethics in practice' diverge. Academic committees are mostly risk-averse and keen to protect institutions from litigation or loss of reputation, while the effort to develop pathways to impact may require taking risks - for example through collaboration with non-researchers, whose effects are often hard to anticipate. Additionally, impactful research would require an end-to-end approach to ethics, at every stage of the research process, from initial design to final delivery of results and possibly, later follow-up with beneficiaries and stakeholders. Tubaro (this special issue) demonstrates the need to include ethics to accompany return of research results to study 
participants, their community, and the wider public. An institutional approval very early on - before data collection, as is commonly done - fails to address issues that arise at a later stage, for example when network visualizations are disclosed (Maya-Jariego, Alieva and Holgado, this special issue).

These considerations suggest that increasing bureaucratization of ethics governance in research institutions is not automatically conducive to more ethical science - whether the term 'ethical' is interpreted as more beneficial, less harmful, etc. Neither can we be sure that research will always gain from corporate-promoted emphasis on voluntary, relatively light ethics as a way to actually escape potentially stricter regulations. A different and more thoughtful approach is needed, and it is up to the research community to create the conditions for its development.

\section{A way forward for SNA researchers ${ }^{4}$}

The recent challenges faced by SNA researchers point towards a fragmented and fuzzy ethical landscape. Despite ethics being a crucial part of scholarly endeavours, there has been increasingly less agreement over what might constitute 'researching in an ethical way' (Hammersley and Traianou, 2011). Ironically, it has been argued that the proliferation of research ethics committees and guidelines may result in closing down ethical discussions rather than in opening up this complex topic (Guillemin, Gillam, Rosenthal and Bolitho, 2012). The current move towards a narrow 'tick box' approach to ethics governance has meant that there has been little space in which to consider the wider ethical debates underpinning epistemology.

Research ethics in [...] the applied social sciences involve ontological, epistemological, theoretical and methodological assumptions embedded within the practice of academic scholarship. These underlying and often taken-for-granted assumptions which researchers accept and use, but which are seldom directly discussed, have moral consequences in scholarly practice (Payne, 2000: 307).

Philosophical ethics are the conceptual heart of research ethics and consist of a range of ethical theories (Schüklenk, 2005). However, these ethical theories are complex, varied and lacking in consensus about what is right and morally justified (Hammersley and Traianou, 2011). In many instances researchers are not clear about the type of ethical approach that underpins their methodology and rarely communicate this to their readers (Payne, 2000). As Milne argues:

Concepts such as informed consent, risk/benefit analysis, and confidentiality are not inherent truths of ethics or categorical imperatives. They are constructs that have emerged from specific ethical philosophies (2005: paragraph 33).

Applied ethics rely on the specific application of normative ethical approaches to disciplines such as the social sciences. Normative ethics consist in setting the moral norms 'which guide, or indicate what one should do or should not do, in particular situations' (Israel and Hay, 2006: 12). Such norms provide a framework for judging decisions and actions relating to what is morally the right thing to do. Nonetheless, there is very little consensus among researchers as to the best and most effective ethical frameworks (Hammersley and Traianou, 2011). It is not our intention to undertake an overall review of all the ethical frameworks. Such overviews exist elsewhere (Comstock, 2012). Nonetheless, for the purposes of this paper, and to underpin our argument, it is necessary to briefly reflect upon the main schools of philosophical ethics; and thus explicitly ground ethical approaches to SNA within these wider debates (something which often has been missing in earlier discussions)

\footnotetext{
4 We acknowledge the contribution of Prof Betsy Thom, Middlesex University, as an earlier version of this section as well as of the section entitled 'Reflexivity and the virtuous researcher' was developed as part of a presentation by herself and Prof Louise Ryan.
} 
Consequential ethical principles, for example, judge the morality of an action by its consequences rather than the intent that lies behind it (Schüklenk, 2005: 6). Despite concerns that this could be used to justify the abuse of research participants on the grounds of beneficial results for the rest of society (Israel and Hay, 2006), this approach has influenced a risk/ benefit analysis that continues to underpin many research methodologies (Milne, 2005). By contrast, non-consequentialist or deontological approaches postulate the existence of an absolute set of moral truths such as 'do not kill' and 'do not lie' which must inform all ethical behaviour (Israel and Hay, 2006: 15). Specifically, such framework underpins the notion of 'informed consent', which researchers have a duty to seek as participants have a moral right to be informed about the nature of and possible risks associated with the study in which they are invited to participate. However, there may be occasions when a participant's rights cannot be regarded as absolute-like when the lives of vulnerable individuals are endangered. In such cases, participant confidentiality and anonymity cannot always be guaranteed and a researcher may be morally justified in revealing the identity of an informant (Scott, Phillips, Moore and Du Plessis, 2005). How can a researcher negotiate these difficult moral dilemmas and weigh up the various ethical questions at stake?

In addressing these questions and other ethical complexities in the field of SNA, we turn to a different school of thought inspired by Aristotelian philosophy. 'Virtue ethics' is an alternative to the just-described approaches which mitigates some of their limitations by emphasizing the moral character of socially-embedded individuals or organizations. The focus is not on the ethics of the act (in this case the research) but rather on the actor (the researcher). The underlying assumption is that a morally upstanding person will act appropriately in all situations. Similarly, human collectives display a level of virtue that is not simply the result of the sum of the virtue of its members (Bright, Winn and Kanov, 2014).

Although liable to criticism of relativism (Israel and Hay, 2006), we see merit in this approach because training social scientists to be 'virtuous agents' can counterbalance the institutionalisation of research governance (McGinn and Bosacki, 2004; Comstock, 2012). As Guillemin and Gillam argue, although the ethical dimension of research practice is often apparent to researchers, 'there is little conceptual work available to draw on to make sense of it. We need both a language to articulate and understand these ethical issues and an approach that assists us to deal with these issues when they arise' (2004: 265). Considering the many ethical challenges facing SNA researchers, as outlined in the previous section, it would be impossible for ethics committees to anticipate and address every conceivable ethical dilemma that may arise in the field. As a way of overcoming this situation, there have been growing calls for creating a community of ethical thinkers (Comstock, 2012). Therefore, as explained in the following sections, we argue for the need to train researchers as 'virtuous agents' who can reflect, collectively, on how to engage with and overcome any ethical dilemma.

\section{Reflexivity and the 'virtuous researcher'}

We argue that one way to enhance ethical thinking is to engage in processes of reflexivity (Guillemin and Gillam 2004; Ryan and Golden, 2006; Ryan, 2020). 'Reflexivity in research is not a single or universal entity but a process - an active, ongoing process that saturates every stage of the research' (Guillemin and Gillam, 2004: 274). Reflexivity as a process of ethical self-examination allows researchers not only to locate themselves as active participants in the research procedure, but also to explore in an open and honest way the impact of the research (both positive and negative) on all those involved in the project (Ryan, Mulholland and Agoston, 2014; Ryan, 2020).

It is within the dimension of 'ethics in practice' that the researcher's ethical competence comes to the fore. By this we mean the researcher's willingness to acknowledge the ethical 
dimension of research practice, his or her ability to actually recognize this ethical dimension when it comes into play, and his or her ability to think through ethical issues and respond appropriately. (Guillemin and Gillam, 2004: 269)

For example, as discussed by D'Angelo and Ryan (in this special issue) visualising social networks may present participants with uncomfortable representations of themselves and their relationships. When the data are visualised in front of the participant, their reactions and sense of unease may cause moments of tension in the research encounter. Likewise, Maya-Jariego, Alieva and Holgado (this special issue) note that in some cultural settings, asking interviewees about 'using contacts' to solve things informally may be interpreted as an inquiry into dubious practices and thus create discomfort. Carefully building the researcher-respondent relationship is essential to avoid misunderstandings.

Reflexivity helps the social network researcher to pause and consider what is going on, to think about how to respond, to react in an appropriate way and to learn lessons about how future such situations might be addressed (for a fuller discussion see Ryan, Mulholland and Agoston, 2014). 'Adopting a reflexive research process means a continuous process of critical scrutiny and interpretation, not just in relation to the research methods and the data but also to the researcher, participants, and the research context' (Guillemin and Gillam, 2004: 275). For example, D'Angelo and Ryan in this special issue share the experience of doing a personal network interview with a young woman, Cynthia, who was caring for her grandmother with dementia and appeared to be very socially isolated. Visualising her sociogram exposed this social isolation to both Cynthia and to the researcher - who felt an urgency to recommend she sought more support from professionals in caring for her grandmother.

Such honest reflexivity, however, is not necessarily easy. Indeed, it cannot be assumed that all researchers have sufficient self-awareness, sensitivity or empathy to acknowledge such a situation, in the context of a research encounter, and to react in an ethically appropriate way. Therefore, we argue that developing such critical reflexivity needs to become part of researcher training programmes so that this skill can be taught and developed over time. While reflexivity may be included in qualitative research methods training courses, it is still less prevalent within quantitative research training (Ryan and Golden, 2006). Chu, Colditz, Sidani, Zimmer and Primack (this special issue) offer an example of reflexivity in quantitative research. Their conscious choice to explicitly reveal the Twitter account of a large cancer advocacy organization while anonymizing everyone in their network, that is, their followers, and followers of followers, is the result of a careful analysis that identified this larger set of followers as potentially at-risk persons.

We see the development of reflexivity as a crucial part of virtuous research ethics. That is not to imply that researchers are in themselves wholly virtuous individuals but rather that they adopt an open, reflexive and morally responsible approach to doing social research. Thus, researchers need to be trained not simply in the best techniques for completing ethics application documents and avoiding litigation but rather in engaging with the complexities and ethical philosophies and learning to adopt moral responsibility:

Virtues are fostered - and indeed related to - particular social contexts and without that social support personal virtues so often weaken... Therefore, if we are wanting virtuous researchers, then we must have 'virtuous research communities' (Pring, 2002 cited in McGinn and Bosacki, 2004: 12).

We suggest that the current procedures of ethical review and ethics committees appear to reduce ethics to a narrow series of questions around methodology; access, consent, anonymity and data protection. Rather than adding future requirements about social network research to this tick box exercise, instead we argue for the extension of research training to ensure that all researchers develop the necessary skills to conduct ethical research in practice. In other words, by developing 
their reflexivity about the messiness of ethics throughout the entire research process, and enhancing their skills to engage with ethical dilemmas we would wish to see an expansion in virtuous researchers or researchers who think ethically.

\section{An ethically engaged SNA community}

Although reflexivity is often discussed as a practice undertaken by an individual researcher or team, we suggest that it can be enhanced as a collective process by embedding and consolidating the insertion of individual researchers into larger reflexive communities. In this way, reflexivity should not be decoupled from a dynamic of collective learning. By sharing critical reflections, best practices and confronting ethical assessments of diverse situations, individual researchers can help the scholarly community to build upon pre-existing efforts to establish ethically responsible conducts. In essence, virtuous researchers are those who inspire, and learn from, a cumulative and cooperative form of reflexivity. This requires a certain degree of openness and even, in some cases, the admissions of mistakes, not all of which can be prevented by rigid protocols and ethical forms. In other words, it requires recognition that good and ethical research is an ever perfectible process of continuous learning.

In this perspective, training is an essential but insufficient step to foster reflexivity if researchers are then left alone to face the highly complex landscape of today's research. As SNA scholars, we are well positioned to appreciate the resources accessible through our peers: the experience and expertise of our colleagues and students, locally and globally. If each research project is in some sense unique, there are commonalities that allow for vicarious learning: for example, we all use visualizations, and we may all face problems such as those discussed in this special issue by D'Angelo and Ryan, Tubaro, and Maya-Jariego, Alieva and Holgado. Gaining insight from one another is a way to look beyond the narrow procedural approaches to ethics governance, and move forward by taking into account possible, but non-obvious mistakes that institutional committees are unlikely to anticipate - such as those against which Chu, Colditz, Sidani, Zimmer and Primack, in this special issue, warn readers. More generally, sharing our experiences for the benefit of others, and conversely discovering how others addressed and solved problems, increases our capacity to think reflectively and responsibly. Thus, we call for a form of 'generalized indirect reciprocity', to use SNA jargon: the information I share helps someone and I benefit from the information given by someone else within our scholarly community, in a virtuous cycle.

We argue that the SNA community will work at its best when collectively addressing ethical dilemmas: the 2005 Social Networks special issue was instrumental to launching discussions on problems such as anonymity and consent in network studies, benefiting from the active contribution of researchers. This special issue is an attempt to revamp that engagement, critically addressing the new challenges that come from recent technological, scientific, legal and political transformations. In developing this project, we submit that a bottom-up approach is most suitable to take into account the real practices of SNA scholars, the concrete issues they encounter and the solutions they devise, rather than leaving the task entirely to top-down ethics committees. Our guiding thread is the desire to contribute worthwhile pathways to devise a way forward, beyond merely reviewing all the current gaps and shortcomings of ethics in SNA.

Overall, we believe the outcome of our efforts strongly supports our call for more reflexivity and more mutual learning through generalized sharing within our scholarly community, in a virtuous circle of indirect reciprocity. Each individual paper in this special issue presents a case in which reflexivity was used to sort out some sensitive ethical problem, and together, they form a set of references that can support decision-making in similar cases and stimulate further reflection. We see 
this as a starting point for the setup of a 'virtuous SNA community' rather than a final achievement. We hope this special issue will be a basis to develop more initiatives - whether they take the form of discussion fora, mailing lists, advice groups or (evolving) guidelines.

\section{References}

Bastin, G., and Tubaro, P. (2018). Le moment big data des sciences sociales. Revue française de sociologie, 59(3):375-394.

Borgatti, S.P., Everett, M.G., and Johnson, J.C. (2013). Analyzing social networks. Sage.

Borgatti, S.P. and Molina, J.L. (2005). Toward ethical guidelines for network research in organizations. Social Networks, 27(2):107-117.

Borgatti, S.P., and Molina, J.L. (2003). Ethical and strategic issues in organizational social network analysis. The Journal of Applied Behavioral Science, 39(3):337-349.

Bright, D.S., Winn, B.A., and Kanov J. (2014). Reconsidering virtue: Differences of perspective in virtue ethics and the positive social sciences. Journal of Business Ethics, 119(4):445-460.

Breiger, R.L. (2005). Introduction to special issue: Ethical dilemmas in social network research. Social Networks, 27(2):89-93.

Chu, K.H., Colditz, J., Sidani, J., Zimmer, M., and Primack, B. (2019, in press). Re-evaluating standards of human subjects protection for sensitive health data in social media networks. Social Networks, https://doi.org/10.1016/j.socnet.2019.10.010.

Comstock, G. (2012). Research ethics: A philosophical guide to the responsible conduct of research. Cambridge University Press.

Cronin, B., Rocha, L., Perra, N., Zhu, Z., Pallotti, F., Gorgoni, S., Conaldi, G., and De Vita, R. (2020, in press). Ethical implications of network data in business and management settings. Social Networks, https://doi.org/10.1016/j.socnet.2020.09.001

D'Angelo, A., and Ryan, L. (2019, in press). The presentation of the networked self: Ethics and epistemology in social network analysis. Social Networks, https://doi.org/10.1016/j.socnet.2019.06.002.

ESRC (Economic and Social Research Council) (2020). What is impact? Website, accessed on $1^{\text {st }}$ May 2020: < https://esrc.ukri.org/research/impact-toolkit/what-is-impact/>

Fort, K., Adda, G., and Bretonnel-Cohen, K. (2011). Last words: Amazon Mechanical Turk: Gold mine or coal mine? Computational Linguistics, 37(2):413-420.

Guillemin, M., and Gillam, L. (2004). Ethics, reflexivity, and 'ethically important moments' in research. Qualitative inquiry, 10(2):261-280.

Guillemin, M., Gillam, L., Rosenthal, D., and Bolitho, A. (2012). Human research ethics committees: Examining their roles and practices. Journal of Empirical Research on Human Research Ethics, 7(3):3849.

Guta, A., Nixon, S.A., and Wilson, M. G. (2013). Resisting the seduction of 'ethics creep': Using Foucault to surface complexity and contradiction in research ethics review. Social Science and Medicine, 98:301-310.

Hammersley, M., and Traianou, A. (2011). Moralism and research ethics: a Machiavellian perspective. International Journal of Social Research Methodology, 14(5):379-390. 
Hogan, B. (2018). Social media giveth, social media taketh away: Facebook, friendships, and APIs.

International Journal of Communication, 12:20, available at: <https://ijoc.org/index.php/ijoc/article/view/6724>

Hoser, B., and Nitschke, T. (2010). Questions on ethics for research in the virtually connected world. Social Networks, 32(3):180-186.

Ingram, D. (2020). Facebook names 20 people to its 'Supreme Court' for content moderation. NBC News, May 6. URL: https://www.nbcnews.com/tech/tech-news/facebook-names-20-people-itssupreme-court-content-moderation-n1201181

Israel, M. and Hay, I. (2006). Research ethics for social scientists. Sage.

Jobin, A., lenca, M. and Vayena, E. (2019). The global landscape of Al ethics guidelines. Nature Machine Intelligence, 1:389-399.

Kadushin, C. (2012). Understanding social networks: Theories, concepts, and findings. Oxford University Press.

Kadushin, C. (2005). Who benefits from network analysis: ethics of social network research. Social Networks, 27(2):139-153.

Kerr, A., Barry, M., and Kelleher, J.D. (2020). Expectations of artificial intelligence and the performativity of ethics: Implications for communication governance. Big Data and Society, 7(1): https://doi.org/10.1177/2053951720915939

Lewis, K, Kaufman, J., Gonzalez, M., Wimmer, A., and Christakis, N. (2008). Tastes, ties, and time: A new social network dataset using Facebook.com. Social Networks, 30(4): $330-342$.

Maya-Jariego, I., Alieva, D., and Holgado, D. (2019, in press). Confidentiality, power relations and evaluation of potential harm in the study of the personal and organizational networks of travel agents in Moscow. Social Networks, https://doi.org/10.1016/j.socnet.2019.10.009.

McGinn, M.K., and Bosacki, S.L. (2004). Research ethics and practitioners: Concerns and strategies for novice researchers engaged in graduate education. In Forum Qualitative Sozialforschung/Forum: Qualitative Social Research, 5(2).

Molina, J.L., and Borgatti, S.P. (2019, in press). Moral bureaucracies and social network research. Social Networks, https://doi.org/10.1016/j.socnet.2019.11.001.

Milne, C. (2005). Overseeing research: Ethics and the institutional review board. In Forum Qualitative Sozialforschung/Forum: Qualitative Social Research, 6(1).

Nissenbaum, H. (2009). Privacy in Context: Technology, Policy, and the Integrity of Social Life. Stanford Law Books.

Payne, S.L. (2000). Challenges for research ethics and moral knowledge construction in the applied social sciences. Journal of Business Ethics, 26(4):307-318.

Ochigame, R. (2019). The invention of 'Ethical Al'. The Intercept, Dec. 20. URL: https://theintercept.com/2019/12/20/mit-ethical-ai-artificial-intelligence/

Robins, G. (2015). Doing social network research. Network-based research design for social scientists. Sage.

Rudolph, A.E., and Young, A.M. (2019, in press). Privacy and confidentiality considerations for collecting HIV risk network data among men who have sex with men and implications for constructing valid risk networks. Social Networks, https://doi.org/10.1016/j.socnet.2019.09.002. 
Ryan, L. (2020, in press). Telling network stories: researching migrants' changing social relations in places over time. Global Networks, https://doi.org/10.1111/glob.12295

Ryan, L., Mulholland, J., and Agoston, A. (2014). Talking ties: Reflecting on network visualisation and qualitative interviewing. Sociological Research Online, 19(2):1-12.

Ryan, L., and Golden, A. (2006). 'Tick the box please': A reflexive approach to doing quantitative social research. Sociology, 40(6):1191-1200.

Schüklenk, U. (2005). Module one: introduction to research ethics. Developing World Bioethics, 5(1): 1-13.

Scott, A., Phillips, H., Moore, A., and Du Plessis, R. (2005). Ethics in practice: conversations about biobanks. Critical Public Health, 15(4):359-368.Tubaro, P. (2019, in press). Whose results are these anyway? Reciprocity and the ethics of 'giving back' after social network research. Social Networks, https://doi.org/10.1016/i.socnet.2019.10.003.

Tubaro, P. (2019, in press). Whose results are these anyway? Reciprocity and the ethics of 'giving back' after social network research. Social Networks, https://doi.org/10.1016/j.socnet.2019.10.003

Tubaro, P., Ryan, L., and D'Angelo, A. (2016). The visual sociogram in qualitative and mixed-methods research. Sociological Research Online, 21(2):80-197.

Wellman, B. (2001). Computer networks as social networks. Science, 293(5537):2031-2034.

Williams, M. L., Burnap, P., and Sloan, L. (2017). Towards an ethical framework for publishing Twitter data in social research: Taking into account users' views, online context and algorithmic estimation. Sociology, 51(6):1149-1168.

Zimmer, M. (2010). 'But the data is already public': on the ethics of research in Facebook. Ethics and Information Technology, 12:313-325. 